\title{
FORMAÇÃO DE CONCEITOS POR CRIANÇAS COM NECESSIDADES ESPECIAIS
}

\author{
Carolina Molina Lucenti de Souza* \\ Luciana Hueara \\ Cecília Guarnieri Batista \\ Adriana Lia Frizsman de Laplane"
}

\begin{abstract}
RESUMO. Processos de formação de conceitos envolvem o estabelecimento de relações entre conhecimentos cotidianos e científicos. Nesse processo, a mediação do adulto e a utilização de materiais que facilitem a construção do conhecimento são essenciais, principalmente no caso de crianças que apresentam dificuldades. Desse modo, o presente estudo buscou observar e analisar a formação de conceitos em um trabalho temático sobre o "Corpo Humano" desenvolvido em um grupo de crianças de 7 a 12 anos com diagnóstico de deficiência visual (baixa visão), a maioria com outras alterações de origem orgânica e queixas de dificuldades escolares. Para a coleta dos dados, as sessões foram videogravadas, transcritas e analisadas. A análise de episódios contribuiu para a compreensão de como as crianças estabelecem relações entre conceitos cotidianos e científicos, para o planejamento dos recursos e materiais pedagógicos a serem utilizados por elas, e ressaltou a importância do contexto de grupo para o desenvolvimento infantil..
\end{abstract}

Palavras-chave: Formação de conceitos; Deficiência visual; Dificuldades escolares.

\section{CONCEPT FORMATION BY CHILDREN WITH SPECIAL NEEDS}

\begin{abstract}
Processes of concept formation involve the establishment of relationships between daily and scientific concepts. Adult mediation and the use of adapted pedagogical resources are seen as important contributors, especially in the case of children with special needs. The present study aimed at the observation and analysis of concept formation in a thematic project about "The Human Body", involving 7-12yr children, with diagnoses of low vision, most of them with other diagnoses of organic problems, and presenting school difficulties. The sessions were filmed, transcribed and analyzed. The analysis of episodes contributed to the understanding of the ways children construct connections between daily and scientific concepts and to the planning of pedagogical resources for children with visual impairments, and highlighted the importance of the group context for child development.
\end{abstract}

Key words: Concept formation; Visual impairment; School difficulties.

\section{FORMACIÓN DE CONCEPTOS POR NIÑOS CON NECESIDADES ESPECIALES}

RESUMEN. Los procesos de formación de conceptos tienen que ver con el establecimiento de relaciones entre conocimientos cotidianos y científicos. En ese proceso, la mediación del adulto y el uso de materiales que faciliten la construcción del conocimiento constituyen factores esenciales, principalmente en el caso de niños que presentan dificultades en el desarrollo. El presente estudio buscó observar y analizar la formación de conceptos en un trabajo temático sobre el "Cuerpo Humano" desarrollado en un grupo de niños de 7 a 12 años, portadores de déficit visual (baja visión), la mayoría con otras alteraciones

Fonoaudióloga da Associação de Pais e Amigos dos Excepcionais de Campinas, Brasil. Especialista em Psicologia do Desenvolvimento e Deficiência pela Universidade Estadual de Campinas, Brasil.

\# Psicóloga. Doutora em Psicologia pela Universidade de São Paulo, Brasil. Professora da Universidade Estadual de Campinas, Brasil.

II Pedagoga. Doutora em Educação pela Universidade Estadual de Campinas. Professora da Faculdade de Ciências Médicas da Universidade Estadual de Campinas. 
de origen orgánica y quejas de dificultades escolares. Los datos fueron construídos a partir de sesiones vídeo-grabadas, transcriptas y analizadas. El análisis de episodios contribuyó para la comprensión de como los niños construyen relaciones entre conceptos cotidianos y científicos, para la planificación de los recursos y materiales pedagógicos a ser utilizados por esos niños, y resaltó la importancia del contexto de grupo para el desarrollo infantil.

Palabras-clave: Formación de conceptos; Déficit visual; Dificultades escolares.

\section{SOBRE O DESENVOLVIMENTO HUMANO}

O estudo sobre o desenvolvimento humano, realizado por diferentes autores, com diferentes referenciais teóricos, tem destacado, sob diversos aspectos, a infância como fase singular do desenvolvimento. Como iniciador da perspectiva histórico-cultural, Vygotsky traz importantes contribuições para a compreensão do desenvolvimento humano, ao discuti-lo como um processo enraizado nas ligações entre a história individual e social do sujeito.

Para Vygotsky (1991), há um papel constitutivo da interação social no processo de desenvolvimento, pois o sujeito é ativo na sua construção como individuo, a partir da interação com o outro em um ambiente sociocultural. É por meio da mediação semiótica, especialmente da linguagem, que essas interações são estabelecidas e que se torna possível significar o mundo, as ações e as pessoas. É por meio dela também, que o sujeito simultaneamente transforma o ambiente em que está inserido e é transformado por ele, pela internalização de práticas culturais, em um movimento dialético constante e ativo. Nesse sentido, Vygotsky rejeita perspectivas preformistas do desenvolvimento humano, considerando que este não se trata de um percurso linear e evolutivo, mas de um processo que implica transformações qualitativas e não lineares ao longo do tempo.

A partir dessa perspectiva, Smolka, Góes e Pino (1997) discutem a (in)determinação do desenvolvimento psicológico, considerando aspectos sócio-culturais do desenvolvimento e o papel da semiótica na interpretação do funcionamento humano. Conforme os autores, a partir do século XX surgiram teorias, dentre as quais a de Vygotsky, que atribuem ao desenvolvimento humano um caráter complexo e dialético, reconhecendo a importância de seus aspectos biológicos, mas considerando-os insuficientes na caracterização do essencialmente humano. Com base nessas teorias, os autores consideram que a determinação das ações humanas e a proposta de um papel constitutivo da realidade social decorrem da interação entre fatores biológicos e culturais. Avaliam ainda, que o locus da determinação, assim como o processo pelo qual as ações humanas são constituídas, não pode ser reduzido às condições biológicas do homem, mas deve considerar o caráter humano determinado pela realidade social de signos produzidos por ele e pelo Outro, dos quais emergem processos significativos.

Smolka, et al. (1997) concluem que a mediação semiótica de Vygotsky colabora para o deslocamento dos esforços em estabelecer fatores internos ou externos de determinação, em direção a uma tentativa de compreensão dos processos de produção, reprodução, transformação e criação de significados e sentidos no funcionamento intersubjetivo. Na mesma direção, Smolka e Nogueira (2002), consideram que o desenvolvimento humano possui uma natureza social e o caracterizam como um desenvolvimento cultural, assumindo que sua dimensão orgânica está impregnada pela cultura e história do sujeito. Essa concepção permite compreender os modos de participação da criança na cultura de maneira dinâmica e dialética. A criança não apenas se apropria e transforma as práticas cotidianas, pois a partir da cultura, ela reelabora em profundidade suas ações, propiciando novas orientações para seu desenvolvimento.

Do mesmo modo, Pino (2005) assume o desenvolvimento psíquico do homem como um desenvolvimento cultural, entendendo que o termo "cultura" conduz à idéia de "produção humana, material ou mental" e implica a ação de um Outro social. Para o autor, a interação tem função importante na construção do indivíduo e da cultura desde os primeiros anos de vida. À medida que as ações da criança recebem a significação que o Outro the confere, ela se constitui como ser cultural, ou seja, como ser humano. Pino (2005) avalia que a abordagem histórico-cultural de Vygotsky é inovadora nesse sentido, por introduzir a cultura como matériaprima do desenvolvimento humano. $\mathrm{O}$ autor considera a cultura como exclusiva e definidora do caráter humano, mas salienta que conferir ao desenvolvimento caráter cultural não significa desconsiderar a importância de aspectos biológicos. $\mathrm{O}$ homem não apresenta duas partes superpostas, uma biológica e outra social: estas são interdependentes na construção do sujeito. 
Considerando o papel da mediação do signo no desenvolvimento, Smolka (2000) problematiza a questão da apropriação das práticas culturais, transcendendo o âmbito da internalização $\mathrm{e}$ deslocando-se para a questão da significação. Avalia que os termos apropriação e internalização podem ser usados como sinônimos quando se pensa no processo de desenvolvimento e aprendizagem como resultado da incorporação pelo sujeito de práticas sócio-culturais, ou seja, quando se considera a existência de algo externo ao sujeito (social) a ser assumido por ele (individual). No entanto, a autora ressalta que o conceito de apropriação corre o risco de ficar restrito aos modos de tornar algo próprio, seu, relacionados apenas a algo adequado, pertinente, aos valores e normas sociais, esquecendo-se que "existem modos de tornar seu, que não são adequados ou pertinentes para o outro" (Smolka, 2000, p.32). Nas relações sociais, o sujeito desempenha diferentes papéis e suas ações assumem diferentes sentidos e significados, que podem ser interpretados pelo outro de muitas maneiras. Assim, é interessante observar que a apropriação é, ao mesmo tempo, social e individual, já que a significados já convencionados pode-se atribuir novos sentidos, de acordo com as experiências individuais de cada um. A discussão levantada por Smolka (2000) amplia as possibilidades de compreensão e análise dos aspectos envolvidos no processo de apropriação, de modo que falas e ações do sujeito consideradas como inadequadas ou impróprias possam ser vistas com outro olhar, e ganhem significado.

Tendo em vista essas considerações, a compreensão do desenvolvimento humano como um conceito amplo, que ultrapassa os limites do orgânico do individuo e considera o papel dos elementos sóciohistóricos na sua constituição, permite que os modos de participação do sujeito na cultura e os sentidos e significados atribuídos por ele sejam entendidos de forma mais dinâmica e dialética. Os processos humanos têm origem nas interações sociais e devem ser compreendidos em seu caráter histórico-cultural. Nesse sentido, é possível dizer que a concepção do sujeito como um ser social, histórico e cultural traz contribuições significativas para a compreensão da atribuição de significados como um processo de construção, desenvolvimento e transformação que ocorre na e pela interação com o outro e com o ambiente histórico-cultural.

\section{FORMAÇÃO DE CONCEITOS}

Na Psicologia muitos autores têm discutido a formação de conceitos, por diferentes perspectivas teóricas e, como salientam Lomônaco, Paula, Mello e Almeida (2001), ainda está longe de haver consenso entre eles no que se refere à definição de conceito e ao seu processo de formação. Entretanto, apesar das diferenças, os autores consideram que existe uma concordância de que os conceitos constituem a representação mental de objetos, eventos e pessoas, e, portanto, uma forma de se conhecer.

Essa questão é abordada do ponto de vista histórico-cultural por Vygotsky, segundo o qual o conhecimento é uma produção social que emerge da atividade humana. Ao realizar um estudo experimental sobre o desenvolvimento dos conceitos, Vygotsky (2001) concluiu que a formação de conceitos envolve um processo que se desenvolve na relação com o meio sociocultural, mediado por signos. $\mathrm{O}$ signo inicialmente se constitui no meio pelo qual ocorre a construção de um conceito, para em seguida tornar-se seu símbolo. Para o autor é a linguagem um dos principais instrumentos de mediação, sendo impossível refletir sobre o pensamento em conceitos sem o pensamento verbal.

A discussão sobre o desenvolvimento conceitual também é realizada por Oliveira (1999) por meio de reflexões sobre o trabalho de Vygotsky. Uma das primeiras noções trazidas pela autora está relacionada aos processos de abstração e generalização que a linguagem possibilita ao homem. Para a autora, a generalização é um ato verbal de pensamento. No que se refere ao conceito em si, considera-o como um instrumento para descontextualização da realidade imediata, ou seja, uma ferramenta, exclusivamente humana, que permite a transição da percepção da realidade para o pensamento.

Além da combinação e generalização de eventos e elementos concretos da experiência, Vygotsky (2001) ressalta que a construção de um conceito envolve a discriminação, abstração e isolamento desses eventos e fatos, bem como a habilidade de examiná-los fora do vínculo concreto e factual em que são dados. Dessa forma, os conceitos não consistem na organização lógica, linear e intrínseca de eventos da experiência. Nas palavras de Vygotsky (2001), "os conceitos não surgem mecanicamente como uma fotografia coletiva de objetos concretos" (p.236).

Oliveira (1999) lembra ainda, que a palavra não se relaciona com um único objeto, mas com todo um grupo ou classe de palavras e não se trata de uma entidade abstrata e fixa, mas um elemento sempre em 
mudança dentro da estrutura psicológica do sujeito. Neste sentido, torna-se bastante pertinente a idéia discutida por Vygotsky (2001), segundo a qual, além do aspecto mais estável, preciso e explicitamente compartilhado do significado das coisas, existe também a zona mais dinâmica do sentido. O sentido de uma palavra é inesgotável e depende da compreensão que o sujeito tem do mundo como um todo e da estrutura interna da personalidade.

Dando continuidade à discussão, Oliveira (1999) considera que os conceitos são elementos de um sistema complexo de inter-relações, portanto não podem ser concebidos como entidades estáveis, já que a interação humana com objetos de ação e de conhecimentos, com os signos, os significados culturais e o Outro é dinâmica e está em constante transformação. Segundo a autora, a própria noção de mediação, internalização e desenvolvimento de Vygotsky impossibilita a concepção de conceitos e redes conceituais acabadas. Conforme Vygotsky (2001), a constituição de um conceito é mediada por outros conceitos, pois nenhum conceito se encontra isolado: "a própria natureza de cada conceito particular já pressupõe a existência de um determinado sistema de conceitos, fora do qual ele não pode existir". (p.359). Os conceitos não estão interligados apenas por relações associativas ou elementos da percepção sensorial, mas pela própria essência da sua natureza e por diferentes relações de generalidade.

Nessa direção, Vygotsky (1993; 2001) faz uma distinção entre conceitos espontâneos e não espontâneos - aspecto analisado por pesquisadores em um simpósio, cujas contribuições originaram o número especial de Mind, Culture, and Activiy, de 1998. Conforme a leitura de Van der Veer (1998) os conceitos espontâneos envolvem conceitos cotidianos, que se referem às experiências pessoais vividas e pouco sistematizadas. Já os não espontâneos constituem os conceitos científicos, interagem com os primeiros e os modificam por meio do aprendizado, principalmente escolar, e da colaboração do adulto. Para Vygostsky (2001), conceitos científicos e cotidianos consistem em processos que diferem tanto pelas vias de desenvolvimento, como pelos modos de funcionamento, mas que, como salienta Mahn e JohnSteiner (1998), estão interligados e se influenciam mutuamente na construção de novos significados e conhecimentos. "Independentemente de se falar em conceitos espontâneos ou científicos, trata-se do desenvolvimento do processo único de formação de conceitos" (Vygotsky, 2001, p. 265).
Conforme Vygotsky (2001), conceitos não espontâneos e espontâneos mantêm relações distintas com a experiência pessoal da criança, pois o processo de aprendizagem e as motivações internas que levam a criança a formar um ou outro ocorrem por vias diferentes. Como aponta Van der Veer (1998), enquanto o conceito cotidiano surge a partir daquilo que a criança vivencia em seu dia-a-dia, ou seja, está mais intimamente relacionado com suas vivências particulares, o desenvolvimento do conceito científico se estabelece pelo que ainda não foi inteiramente desenvolvido nos conceitos cotidianos, através da relação do sujeito com os objetos e outros conceitos elaborados anteriormente. Pode-se dizer que o domínio de conceitos científicos pela criança não implica na substituição dos conceitos cotidianos, mas sim na reconstrução e ampliação dos conceitos espontâneos anteriormente constituídos.

Nesse sentido, Vygotsky (2001) avalia a aprendizagem como um elemento fundamental no processo de formação dos conceitos pela criança, principalmente no que se refere aos conhecimentos científicos. Para o autor, a idade escolar é o período decisivo e a aprendizagem o fator fundamental para o desenvolvimento intelectual, pois favorece a tomada de consciência e se constitui em elemento importante para o processo de generalização de conceitos. Vygotsky (1991) considera que no processo de aprendizagem os conceitos científicos podem ser construídos com a colaboração do adulto ou do parceiro. No primeiro caso, o adulto desempenha um papel importante, pois apresenta conhecimentos mais sistematizados e é capaz de organizar seu pensamento de forma mais clara, propiciando meios para que a criança possa organizar seus próprios pensamentos. Conforme o autor, a mediação do adulto permite que funções não dominadas autonomamente pela criança sejam realizadas em conjunto, de forma compartilhada. Desse modo, a qualidade do ensino, a concepção que o adulto tem da aprendizagem, seus métodos e perspectivas se mostram elementos fundamentais para o desenvolvimento cognitivo da criança.

A partir da leitura de Van der Veer (1998) e Vygotsky (2001) é possível verificar diferenças bem delineadas entre os conceitos científicos e cotidianos. O conceito científico implica uma apresentação verbal, traz uma organização sistêmica, lógica e hierárquica, e demanda o uso consciente e deliberado da criança. Por outro lado, o conceito cotidiano surge no contexto da vida diária, como resultado da interação da criança com o adulto e com o ambiente não-social. Dispensa 
uma apresentação verbal explícita, não se constitui de forma coerente e hierarquicamente organizada, e geralmente não é utilizado de modo consciente e deliberado.

Os autores concordam que o uso de conceitos científicos e cotidianos traz vantagens, e, também, possíveis desvantagens. Os conceitos científicos apresentam uma estrutura conceitual interligada, que constitui modelos que buscam refletir a natureza complexa dos objetos de estudo. $\mathrm{Na}$ escola, as crianças realizam reflexões sobre as propriedades formais desses conceitos, e constroem relações destes com outros conceitos. No entanto, esses conceitos podem permanecer vazios de sentido (embora com significado), como raciocínios verbais sem conexão estabelecida com o "mundo real", e serem facilmente esquecidos. Por outro lado, Van der Veer (1998) e Vygotsky (2001) consideram que os conceitos cotidianos são ricos em implicações práticas, e por isso são dificilmente esquecidos. Contudo, podem representar possíveis riscos por estarem baseados em condições válidas apenas para determinadas situações, dado que não partem de um sistema de conceitos logicamente organizado. Considerados dessa forma, podemos afirmar que o conhecimento conceitual ideal está baseado na combinação das contribuições dos conceitos científicos e cotidianos, o primeiro por favorecer a sistematização, o segundo, pela construção de sentidos nas relações com as experiências e vivências de cada um.

Como explicitado anteriormente, tanto os conceitos científicos como os espontâneos não são dados, mas construídos ativamente pelo sujeito por meio de interações com o outro e com o ambiente histórico-cultural que o envolve. A formação de novos conceitos é processual e envolve a constituição de vínculos entre diferentes conceitos e suas relações de generalidade. Nesse processo, conceitos científicos e espontâneos se encontram, de forma que os conceitos adquiridos na escola e no cotidiano não estão separados, e podem, ou devem, coexistir em constante interação.

Tendo em vista a importância da promoção de situações que favoreçam o desenvolvimento de crianças com necessidades especiais, a discussão de questões relacionadas ao aprendizado de conhecimentos científicos e aos modos de intervenção que possam favorecê-lo se tornam ainda mais relevantes. Nesse sentido, o presente estudo buscou observar e analisar a apreensão de conceitos em um trabalho temático sobre o "Corpo Humano" desenvolvido em um grupo de convivência de crianças com necessidades especiais.

\section{METODOLOGIA}

\section{Ambiente de coleta de dados}

Os dados foram coletados no contexto das atividades do Grupo de Avaliação e Intervenção do Desenvolvimento Infantil (7-12 anos) de um centro universitário. Trata-se de um grupo de convivência infantil inserido em um projeto integrado de pesquisa e intervenção para a promoção do desenvolvimento de crianças com deficiência visual (baixa visão/cegueira), algumas com outras alterações do desenvolvimento e dificuldades escolares. Nele atuam psicólogos, pedagogos e fonoaudiólogos. O grupo tem como meta propiciar condições que favoreçam o processo de desenvolvimento e inserção dessas crianças em escolas regulares ou em outros tipos de recursos da comunidade. As atividades propostas - contar e elaborar histórias, jogos, desenho, modelagem e brincadeiras de vários tipos - estão relacionadas aos objetivos escolares (leitura, escrita, matemática, conhecimentos em geral), buscando-se formas alternativas e significativas de apresentação dos mesmos. As sessões, com duração de 90 minutos, ocorrem semanalmente em sala e/ou pátio, seguidas por período de lanche.

\section{Participantes}

Participaram do estudo crianças de 7-12 anos, todas com diagnóstico de deficiência visual (baixa visão) e, na maioria dos casos, com diagnósticos de outros problemas de origem orgânica e/ou alterações no desenvolvimento. Todas estavam matriculadas em escola regular ou especial e apresentavam dificuldades de aprendizagem. Do conjunto de episódios analisados, foram selecionados para o presente relato três episódios representativos das questões de estudo, focando duas crianças, descritas a seguir.

Sofia ${ }^{1}$, nove anos e um mês ${ }^{2}$, diagnósticos médicos de baixa visão, fotofobia, acromatopsia com ambliopia e elevado grau de hipermetropia, diabetes tipo 1 (insulina $2 \mathrm{x}$ ao dia), e hiperatividade (diagnóstico feito por vários profissionais, embora não por nossa equipe). Freqüentava a escola regular com queixa de agressividade, sem dificuldades de aprendizagem. Nas atividades nos grupos, mostrava boa capacidade de compreensão das tarefas, e, em vários momentos, agressividade com os colegas e

Todos os nomes de crianças são fictícios. Os pais assinaram o Termo de Consentimento Livre e Esclarecido

2 A idade das crianças se refere ao período inicial da coleta de dados. 
adultos do grupo. Apesar do diagnóstico de acromatopsia, nas diferentes tarefas no grupo, mostrou discriminação de cores.

Gisela, dez anos e nove meses, diagnóstico médico de baixa visão, toxoplasmose ocular com calcificações cerebrais. Teve um histórico de ingresso e rejeição em uma pré-escola, permaneceu na segunda pré-escola até oito anos, e ingressou no Ensino Fundamental com nove anos, sempre com queixas relativas à curta permanência nas atividades propostas e dificuldades de aprendizagem. No ano do início do presente projeto, estava consolidando o processo de alfabetização.

\section{Procedimento}

Foram realizadas doze sessões em grupo, cujo tema era "Corpo Humano", durante as quais, foram trabalhados os sistemas digestivo, respiratório, urinário e circulatório. Para tanto, foram utilizados materiais adaptados, como esquemas tateáveis, e realizadas atividades demonstrativas do funcionamento dos sistemas. A rotina dos atendimentos envolvia, inicialmente, o levantamento de conhecimentos e experiências do cotidiano das crianças sobre o tema que seria abordado (engasgos, cortes com sangramento, identificação do batimento cardíaco, vício do cigarro, entre outros). Em vários casos, foram realizadas vivências de atividades relativas ao tema do dia, incluindo, por exemplo, ausculta dos batimentos cardíacos com estetoscópio, experiência com filtragem, entre outros. Em seguida, o adulto oferecia explicações formais sobre esses conhecimentos, utilizando material previamente preparado e relacionando as explicações às experiências previamente relatadas e vivenciadas pelas crianças.

As sessões duraram aproximadamente uma hora. Todas foram gravadas, transcritas e analisadas. Os dados obtidos foram organizados em episódios escolhidos como unidade de análise, a fim de possibilitar o rastreamento de aspectos interessantes ao trabalho. A metodologia por análise microgenética de episódios foi baseada em Góes (2000) e Pedrosa e Carvalho (2006). Nos episódios escolhidos procurouse identificar as relações estabelecidas pelas crianças entre conceitos cotidianos e científicos relacionados ao tema. Buscou-se caracterizar, de modo especial, competências e iniciativas das crianças, diferentes modos de atuação do adulto e situações de interação estabelecidas entre parceiros, em que estes contribuíam para a construção conjunta de conhecimentos.

\section{RESULTADOS}

A análise dos dados possibilitou a identificação de episódios que exemplificam o desenvolvimento de conceitos científicos e cotidianos e as relações estabelecidas entre eles por crianças com necessidades especiais. Para o presente relato foram selecionados quatro episódios, descritos a seguir, que exemplificam algumas das análises realizadas.

\section{Episódio 1: O exame de sangue}

Durante a discussão sobre o sistema circulatório, Sofia disse: "Falando em sangue, esses dias eu fui tirar sangue". Diante da fala da criança, o adulto perguntou como se fazia para tirar sangue. Sofia explicou e demonstrou com as mãos os procedimentos envolvidos: amarrar o garrote, fechar a mão e colocar a seringa. Em seguida, Gisela perguntou: "E depois? E depois o que acontece com o sangue, Sofia? Ele vai pra onde?" Sofia respondeu: "Eles colhem. Eles colhem um vidrinho assim (Sofia indica com as mãos o tamanho do vidro) e mandam lá pro laboratório." Interessada, Gisela fez uma nova pergunta: "Pra fazer o que lá?" E Sofia prosseguiu com a explicação: "Pra investigar, pra saber se a gente tem algum problema de saúde."

De acordo com Vygotsky (1991) o conhecimento é fruto das interações sociais estabelecidas pela mediação dos signos culturais, principalmente a linguagem, construídos na coletividade. Neste episódio verifica-se que, por meio da interação entre as crianças e da troca de experiências, a situação de grupo favoreceu a construção conjunta de significados. Ao discutir a importância do grupo para o processo terapêutico, Panhoca (1997) destaca que os participantes de um grupo atuam como mediadores entre a cultura e o sujeito promovendo processos interpsicológicos que serão posteriormente internalizados. Neste trecho, Sofia retoma e compartilha experiências rotineiras (devido ao diabetes, Sofia faz exames de sangue com frequiência) que instigam Gisela e a auxiliam na constituição de um novo conhecimento. Ou seja, Sofia age como mediadora entre um conhecimento que faz parte de sua cultura e Gisela. Desse modo, observa-se que o grupo, como discutido pela autora, pode proporcionar atividades lingüísticas e sociais em que o contexto sociocultural de seus participantes, o ambiente onde as atividades são desenvolvidas e os diferentes papéis desempenhados pelas crianças se relacionam e propiciam a construção de novos conceitos.

No caso de Sofia, a vivência de diferentes papéis se mostra ainda mais importante, uma vez que a 
criança geralmente é vista no contexto escolar e familiar mais por suas dificuldades que por suas habilidades. As principais queixas apresentadas nesses contextos são relativas à hiperatividade, déficit de atenção, comportamento inadequado, agressividade e dificuldades de interação com parceiros. Entretanto, o contexto de grupo permitiu que Sofia estabelecesse e sustentasse interações com o parceiro assumindo um papel diferente do que lhe é geralmente atribuído. No episódio apresentado, Sofia ouviu e respondeu às perguntas do outro com interesse, atenção, clareza, assertividade e respeito, colocando-se no papel de quem "ensina" e criando um ambiente propício para a construção de novos conhecimentos. Além disso, a postura assumida por Sofia e o modo como ela conduziu a exposição do assunto favoreceu a participação de colegas como Gisela que, apesar de apresentar dificuldade em se interessar por explicações formais, permaneceu interessada e atenta à explicação.

Em várias situações no grupo, tinham sido observadas disputas entre Sofia e Gisela. O adulto sinalizava sua desaprovação, mas, principalmente, buscava, constantemente, criar situações que propiciassem diálogos entre as crianças, ao propor temas e tarefas potencialmente interessantes para as crianças. Uma vez iniciados esses diálogos, seu papel era o de manter-se na retaguarda, mas sempre atento ao que se passava, de forma a captar o significado e, de forma discreta, propiciar situações de cooperação.

Quando se trata da interação entre parceiros, é importante considerar que a criança pode assumir um papel ativo no processo de construção de significados e no desenvolvimento e transformação de si mesmo, do outro e da cultura. Como verificado no trecho acima, nem sempre o adulto é o único parceiro competente: a criança, muitas vezes, influenciada por suas experiências, também é capaz de trazer contribuições para o desenvolvimento do outro e para a constituição de novos saberes. $\mathrm{O}$ adulto, como mediador, pode propiciar, ativamente, esses momentos.

\section{Episódio 2: Insulina}

$\mathrm{Na}$ sessão em que foi apresentado o sistema digestivo, o cartaz utilizado como apoio à explicação formal continha o desenho de: boca, esôfago, estômago e intestino. Durante a explicação do adulto, Sofia perguntou sobre o pâncreas, demonstrando interesse por seu funcionamento, motivo pelo qual a representação deste órgão foi incluído ao material utilizado na sessão subseqüente. Nesta sessão, o adulto inicialmente perguntou se alguém conhecia o novo órgão. Sofia respondeu que se tratava do pâncreas. Durante a explicação de seu funcionamento, $\mathrm{o}$ adulto disse que o pâncreas produz a insulina e perguntou: "Quem sabe o que é insulina?". Sofia imediatamente respondeu: "É um negócio que aplica assim na gente... é assim, um líquido assim.”. A partir da fala da criança o adulto explicou que a insulina é aplicada em pessoas cujo pâncreas não funciona bem. Diante disso, Sofia comentou: "O meu não funciona”.

Este episódio exemplifica como a atuação do adulto, atento às ações da criança, pode se modificar, dependendo dos modos de participação a cada etapa de um projeto. A esse respeito, Góes (1995) ressalta a importância da contribuição do outro como uma ação partilhada, uma ajuda, um estabelecimento de ponte e criação de estrutura de suporte. Considera que a relação entre a ação do outro e a ação do sujeito é de caráter constitutivo, partilhada e não direcionada. Lembra ainda que a ação do adulto não determina, plenamente ou unidirecionalmente, o funcionamento da criança. Assim, quando se pensa que as ações do outro afetam o sujeito, nem sempre é fácil dizer o que elas propiciaram construir e como isso se deu. Em outras palavras, é impossível ditar previamente que uma determinada ação do adulto desencadeará necessariamente certa reação da criança.

$O$ fato de Sofia ter diabetes e interesse, demonstrado na semana anterior, pelo funcionamento do pâncreas, fez com que as mediadoras preparassem um material específico que complementasse com informações científicas o conhecimento cotidiano da criança sobre este órgão. Neste trecho, a atuação do adulto, no sentido de possibilitar a participação das crianças de forma mais espontânea e livre de pressões, e sua sensibilidade às vivências das crianças, permitiu um diálogo sobre o sistema digestivo, cada vez mais complexo, sempre interligando conhecimentos cotidianos e científicos.

Góes (1995), ao discutir a mediação pedagógica, considera que em situações de aprendizado o que se pode fazer é projetar um cenário, derivando formas potenciais de atuação do outro, isto é, escolher possibilidades e nelas investir, em função de objetivos e metas determinadas. Assim, o planejamento de atividades, especialmente no caso da criança com necessidades especiais, não deve ser totalmente prédeterminado, dependendo, em grande parte, de sua reação e receptividade às propostas. A abordagem deve considerar a criança em interação, assumindo seu papel na construção conjunta de significados e conhecimento. A ação partilhada possibilita um processo de desenvolvimento permanente, que 
envolve o indivíduo e seu meio sociocultural numa interação constante.

Nesse episódio, especificamente, observa-se ainda a forte relação entre a experiência pessoal da criança e a construção de um novo conhecimento. No caso de Sofia, a vivência do diabetes repercute no sentido que ela atribui aos conceitos apresentados, e nos significados construídos. Conforme esclarecem Góes e Cruz (2006) ao discutirem o trabalho de Vygotsky, há uma relação estreita entre sentido e o contexto. $\mathrm{O}$ contexto torna os sentidos ilimitados, os faz inacabados, dependentes da interpretação de mundo e da personalidade do sujeito. Deste modo, pode-se dizer que os sentidos ampliam os significados e os conceitos, tornando-os peculiares para cada indivíduo. Considera-se que Sofia possuía, a partir de suas experiências, uma noção prática do que era insulina (conceito cotidiano) e que, por meio da explicação formal do adulto, passou a ter mais noções sobre o funcionamento da substância e processos fisiológicos envolvidos (conceitos científicos). Também para as outras crianças, ouvir falar de diabetes como uma doença da colega, e explicada por ela, assumiu sentidos e significados completamente diferentes de uma explicação teórica sobre doenças, em relação às quais nenhum membro do grupo tinha experiência direta ou indireta. Dessa forma, observa-se nesse episódio um exemplo da consideração de Vygotsky (1997) a respeito da interação entre aprendizado e desenvolvimento. Para o autor, qualquer situação de aprendizado da criança encontra uma história prévia marcada por sua experiência de vida. Assim, o aprendizado não sistematizado oferece subsídios para a construção de um conhecimento sistematizado, produzindo algo novo no desenvolvimento da criança. Nesse sentido, a aprendizagem se revela um elemento importante para o processo de formação dos conceitos infantis, principalmente quando se trata de conceitos científicos.

Nesse episódio, a situação de ensinoaprendizagem se mostrou um elemento contribuinte para ao processo de constituição como sujeito. No trecho em questão, a discussão com o adulto sobre o funcionamento do sistema digestivo, especificamente o pâncreas, trouxe indícios de que Sofia passou a compreender melhor o que acontecia consigo em relação ao diabetes após a explicação do adulto.

\section{Episódio 3: O engasgo}

O sistema respiratório foi abordado em várias sessões. Na primeira delas, o adulto apresentou os órgãos que o constituíam e ofereceu uma explicação sobre sua fisiologia. Durante a exposição, o adulto realizou algumas comparações com o sistema digestivo (tema trabalhado anteriormente), explicou o mecanismo da deglutição e explicou o que ocorre quando uma pessoa engasga. No inicio da sessão seguinte, o adulto mostrou novamente o esquema sobre o aparelho respiratório e perguntou às crianças se elas se lembravam dele. Nesse momento, Gisela disse que tinha algo para contar: "Ontem a minha irmã engasgou aqui na traquéia”. Enquanto falava, Gisela colocou a mão no pescoço indicando a localização da traquéia. $\mathrm{O}$ adulto perguntou com que ela tinha engasgado e Gisela respondeu: "Comendo alguma coisa. Daí ela tossiu. Aí eu falei: 'Não! Essa coisa não entra aí na traquéia!' Aí eu falei pra ela que não podia entrar. Daí ela tossiu." Pouco depois, comentando sobre a trajetória do alimento e dizendo que este passava por trás da traquéia, o adulto perguntou para as crianças: "Aí vai para onde, se ela não vai para a traquéia?". Gabriela respondeu: "Vai pro esôfago!".

Neste episódio, conceitos cotidianos, construídos com base na experiência pessoal da criança se transformam com a exposição aos conceitos científicos, propiciando a construção de conhecimento. O conhecimento formal trazido pelo adulto (fisiologia da respiração e digestão) auxiliou a criança a organizar e compreender um conhecimento já existente, vivenciado rotineiramente - engasgo. $\mathrm{O}$ trecho demonstra como conhecimento científico e cotidiano podem ser construídos ativamente pelo sujeito na relação com o outro e o ambiente, exemplificando a concepção vygotskyana de conceitos como construções dinâmicas resultantes da interação do sujeito com objetos de ação e de conhecimento, com a cultura e com o outro, em situações de construção conjunta e negociada de significados.

A mediação do adulto e a utilização de materiais que facilitem a construção do conhecimento são fatores essenciais para a apreensão de conceitos científicos, principalmente nos casos de crianças com dificuldades. Na situação apresentada foi possível verificar que os esquemas confeccionados com materiais acessíveis e atrativos às crianças com ou sem deficiência visual favoreceu a compreensão de Gisela. Durante a exposição do tema, houve momentos em que os esquemas do aparelho respiratório e digestivo foram contrapostos, para esclarecer às crianças que se tratava de dois aparelhos distintos, mas próximos e interligados. A fala de Gisela, retomando com propriedade os conceitos trabalhados, demonstrou que o modo como o material foi confeccionado e utilizado como apoio à explicação formal do adulto permitiu que a criança compreendesse a distinção relativa não 
apenas à localização e denominação dos órgãos constituintes dos sistemas, mas também entre suas funções.

Cabe destacar ainda que, na situação apresentada, Gisela relatou a transposição de discussões realizadas em sessão para seu cotidiano, o que merece uma atenção especial por evidenciar a compreensão do assunto pela criança. $\mathrm{O}$ fato de Gisela resgatar em uma situação cotidiana a explicação formal realizada pelo adulto em contexto de aprendizagem, exemplifica as considerações de Vygotsky sobre a formação de conceitos como uma aquisição processual que envolve a conexão entre diferentes tipos de conceitos cotidianos ou científicos - e suas relações de generalidade.

Nesse caso, a situação de aprendizagem mediada pelo adulto e compartilhada com parceiros, auxiliou na sistematização de um conhecimento cotidiano, propiciando algo novo no desenvolvimento da criança: o início da construção de um conceito científico. Essa maneira de apresentar os conhecimentos científicos, considerando as necessidades, interesses e possibilidades da criança, favorece o desenvolvimento infantil. No trecho apresentado, a tentativa do adulto de relacionar conceitos científicos com experiências cotidianas da criança propiciou o interesse, participação e concentração - o que é especialmente importante no caso de Gisela, caracterizada por queixas escolares de atenção reduzida e pouca permanência em atividades mais estruturadas. Essas considerações estão em consonância com Cavalcanti (2005), quando afirma que, para compreender o processo de formação de conceitos por meio da aprendizagem formal, deve-se considerar as especificidades e as relações entre conceitos científicos e cotidianos: conceitos espontâneos e não-espontâneos estão em constante interação e, embora sofram influência de fatores internos e externos, constituem-se um processo único, dinâmico e não acabado.

\section{DISCUSSÃO}

A análise dos episódios mostrou que a explicação formal de conhecimentos científicos, de uma forma que incorpora experiências pessoais das crianças e, deste modo, se aproxima da realidade de cada uma delas, pode trazer alternativas favoráveis ao aprendizado de crianças com necessidades especiais. A evocação de vivências das crianças relacionadas ao tema do projeto (Corpo Humano) se revelou um meio de provocar a articulação de conceitos cotidianos e científicos, além de sustentar o interesse de todos na questão e de suscitar a participação das crianças na própria apresentação dos conhecimentos formais. Os conhecimentos cotidianos trazidos pelas crianças constituíram a base sobre a qual se estabeleceu o significado dos conceitos científicos e, assim, favoreceram a construção dos significados formais. Por outro lado, o domínio de conceitos científicos permitiu que elas enxergassem de nova forma o mundo cotidiano em que as envolve.

Crianças com deficiência geralmente são caracterizadas por suas dificuldades, mais que por suas capacidades, e correm o risco de serem objeto de prognósticos desfavoráveis em relação às suas possibilidades de aprender. No entanto, o presente estudo demonstrou que, dadas condições favoráveis, é possível propiciar situações que favoreçam a construção de novos conhecimentos por essas crianças. Nesse sentido, as análises dos episódios apontaram para o papel do grupo no desenvolvimento infantil. Por meio das interações com o adulto e com parceiros, as crianças vivenciaram diferentes papéis e diferentes situações. Puderam assumir a liderança em determinados momentos e, em outros, receber informações e compartilhar experiências com parceiros que dominavam diferentes experiências e competências. Também puderam vivenciar situações de sucesso, fracasso, conflitos e negociação de regras sociais, que favoreceram seu processo de desenvolvimento e a aquisição de novos conhecimentos.

Não menos importantes, os modos de apresentar o conhecimento e os materiais e estratégias utilizadas para tanto, também se mostraram relevantes no processo de formação de conceitos por crianças com necessidades especiais. O planejamento dos materiais utilizados em atividades educativas procurou atender tanto a crianças sem alterações como aquelas com problemas visuais severos. Neste trabalho, por exemplo, houve o cuidado de confeccionar materiais que pudessem ser perceptíveis tanto ao tato (presença de relevo), devido à presença de uma criança com baixa visão severa, como à visão (uso de ampliação e contraste) pelas demais crianças, com baixa visão leve a moderada. As atividades incorporavam exemplos práticos que permitiam a participação de todas as crianças, tais como ausculta do batimento cardíaco, percepção da pulsação no punho e pescoço, percepção da respiração pelo sopro, entre outras experiências. No que se refere ao preparo de materiais acessíveis às crianças cegas, em trabalho anterior, Batista (2005) considerou que não se trata, apenas, de substituição da visão pelo tato, uma vez que este não constitui um substituto direto da visão. Salientou que a formação de conceitos envolve, além do aporte das informações por 
via sensorial, processos cognitivos e sociais. Nessa direção, as observações realizadas no presente trabalho sugerem que o uso de materiais adaptados, per se, não é suficiente para a compreensão de conceitos científicos. É necessário que o resgate da experiência cotidiana ocorra em conjunto com a explicação e apresentação de um material formal, propiciando diferentes modos de significação, favorecendo a compreensão de novos conceitos.

Dessa forma, crianças que eram constantemente identificadas e tratadas com base nos diagnósticos de seus problemas de origem orgânica, mostraram competências e capacidades, quando oferecidos materiais adequados às suas necessidades e em situação de grupo. A mediação do adulto, ao propor atividades em grupo e elaborar recursos para sua execução, ao se mostrar sensível aos interesses das crianças e favorecer a interação entre elas, permitiu a ampliação de suas competências. Assim, a proposta rompeu um círculo vicioso atrelado a expectativas pessimistas, criando um círculo virtuoso, propício ao desenvolvimento.

\section{REFERÊNCIAS}

Batista, C. G. (2005). Formação de conceitos em crianças cegas: questões teóricas e implicações educacionais. Psicologia Teoria e Pesquisa, 21(1), 7-15.

Cavalcanti, L. S. (2005). Cotidiano, mediação pedagógica e formação de conceitos: uma contribuição de Vygotsky ao ensino de geografia. Cadernos Cedes, 25(66), 185-207.

Góes, M. C. R. (1995). A construção de conhecimentos Examinando o papel do outro nos processos de significação. Temas em Psicologia, 2, 23-29.

Góes, M. C. R. (2000). A abordagem microgenética na matriz histórico-cultural: uma perspectiva para o estudo da constituição da subjetividade.Cadernos Cedes, 20(50),9-25.

Lomônaco, J. F. B., Paula, F. V., Mello, C. B. \& Almeida, F. A. (2001). Desenvolvimento de Conceitos: O Paradigma das Transformações. Psicologia: Teoria e Pesquisa, 17(2), 161-168.
Mahn, H. \& John-Steiner, V. (1998). Introduction.Mind, culture, and activity, 5(2),81-88.

Oliveira, M. K. (1999). Três questões sobre desenvolvimento conceitual. Em M.B

Oliveira \& M. K. Oliveira (Org.). Investigações cognitivas: Conceitos, linguagem e cultura (pp. 55 - 64). Porto Alegre: Artmed.

Panhoca, I. (1997). O grupo terapêutico fonoaudiológico e sua articulação com a perspectiva histórico-cultural. Em Tempo de Fonoaudiologia III. São Paulo: Cabral; p. 5-24.

Pedrosa, M. I. \& Carvalho, A. M. A. (2006). Análise qualitativa de episódios de interação: uma reflexão sobre procedimentos e formas de uso. Psicologia: Reflexão e Crítica. 18(3), 431-442.

Pino, A. (2005). A criança, um ser cultural ou da passagem do biológico ao simbólico. Em A. Pino. As marcas do humano: as origens da constituição cultural da criança na perspectiva de Lev S. Vigotski (pp. 43-68). São Paulo: Cortez.

Smolka, A. L. B. (2000). O (im)próprio e o (im)pertinente na apropriação das práticas sociais. Cadernos Cedes. (50), 26-40.

Smolka, A. L. B., Góes, M. C. R. \& Pino, A. (1997). In Determinacy and the semiotic constitution of subjectivity. In A. Fogel, M.C.D.P Lyra \& J.Valsiner (Org). Dynamics and indeterminism in developmenal and social processes (Vol.I, pp. 153-164). Mahwah, New Jersey: Lawrence Erlabaum Associates, Publishers.

Smolka, A. L. B. \& Nogueira, A. L. H. (2002). O desenvolvimento cultural da criança: mediação, dialogia e (inter)regulação. Em Psicologia, educação e as temáticas da vida contemporânea (pp.77-94). São Paulo: Moderna.

Van Der Veer, R. (1998). From concept attainment to knowledge formation. Mind, culture, and activity, 5(2), 89-94.

Vygotsky, L. S. (1991). A formação social da mente: o desenvolvimento dos processos psicológicos superiores. 4.ed. São Paulo: Martins Fontes.

Vygotsky, L. S. (1993). Pensamento e Linguagem. São Paulo: Martins Fontes.

Vygotsky L. S. (2001). A construção do pensamento e da linguagem. (Trad: Paulo Bezerra). São Paulo: Martins Fontes.

Recebido em 28/08/2008 Aceito em 19/03/2010

Endereço para correspondência: Cecília Guarnieri Batista. Av. N. S. Fátima, 805, Acapulco, 111, CEP 13076-903, CampinasSP, Brasil. E-mail: cecigb@fcm.unicamp.br. 